\title{
Global Connections: Telemedicine as a Tool to extend Trauma Education
}

\author{
Antonio C Marttos, Fernanda M Kuchkarian, Daniel F Rojas, Gustavo P Fraga, Francisco S Collet-Silva, \\ Cleinaldo de Almeida Costa, George D Garcia, Enrique Ginzburg, Carl I Schulman, Nicholas Namias
}

\begin{abstract}
Introduction: Telemedicine is revolutionizing the delivery of trauma care and education. The International Trauma TeleGrand Rounds is a series that unites institutions worldwide to discuss complex clinical cases and advanced trauma and critical care topics.
\end{abstract}

Materials and methods: Multiple remote institutions connect simultaneously to discuss the management of a trauma patient from the prehospital phase to discharge. Weekly, a case is presented in English by one institution on a rotating basis. Key points include mechanism of injury, resuscitation, laboratory and imaging diagnostics, surgical interventions, postoperative patient care, evaluation of treatment decisions and review of the literature. The highly interactive format allows participants to evaluate differences in trauma care across international health systems.

Results: During 2010 to 2011,68 sessions were documented. Cases include blunt $(42.6 \%)$, penetrating $(48.5 \%)$, blast $(7.4 \%)$ and crushing $(1.5 \%)$ traumas. Gunshot wounds were the most frequent (25\%). A holistic range of injuries were represented including injuries to major arteries, veins, lungs, heart, pericardium, esophagus, diaphragm, abdominal wall, stomach, intestines, liver, kidneys, pelvis, and the extremities. A variety of surgical and nonsurgical interventions were explored. To date, there have been 42 participating institutions from the United States, Brazil, Colombia, Bahamas, Canada, Mexico, Venezuela, Argentina, Panama, Puerto Rico, Dominican Republic, British Virgin Islands, Spain, Thailand, Turkey and Iraq; ranging from academic medical centers military hospitals, community hospitals, and rural hospitals. In 2011, the series received accreditation by the Accreditation Council for Continuing Medical Education.

Conclusion: Telemedicine offers a solution to address the disparities in access to trauma care and education. The diversity of institutional settings allows participants to learn from others on how to best treat trauma patients, despite differences in resources and expertise. In addition to serving as an educational tool, the series provides a mechanism for physicians to network and collaborate on future endeavors.

Keywords: Telemedicine, Trauma, Surgical education, Videoconferencing, Distance education, Grand rounds.

How to cite this article: Marttos AC, Kuchkarian FM, Rojas DF, Fraga GP, Collet-Silva FS, de Almeida Costa C, Garcia GD, Ginzburg E, Schulman Cl, Namias N. Global Connections: Telemedicine as a Tool to extend Trauma Education. Panam J Trauma Critical Care Emerg Surg 2013;2(1):62-66.

Source of support: Nil

Conflict of interest: None declared

\section{RESUMEN}

Introducción: La telemedicina está revolucionando los métodos de distribución de cuidado y educación traumatológica. Las "International Trauma Tele-Grand Rounds" (Tele-Rondas Internacionales de Trauma) son una serie que atrae instituciones alrededor del mundo para discutir cases clínicos complejos y temas avanzados de traumatología y cuidados intensivos.

Métodos: Múltiples instituciones remotas se conectan simultáneamente para discutir el manejo de una víctima de un traumatismo desde la fase pre-hospitalaria hasta que se le da de alta. Cada semana hay una rotación en cuanto a la institución que presenta el caso en Ingles. Los puntos principales incluyen mecanismo de lesión, resucitación, exámenes de laboratorio y radiológicos, y análisis de literatura. El formato altamente interactivo de la conferencia permite que los participantes evalúen las diferencias de cuidados traumatológicos en centros médicos alrededor del mundo.

Resultados: Desde el 2010-2011, 68 sesiones fueron documentadas. Los casos incluyeron trauma contundente $(42.6 \%)$, penetrante $(48.5 \%)$, explosivo $(7.4 \%)$, y de aplastamiento (1.5\%). Las heridas másfrecuentesfueron de bala $(25 \%)$. Un rango holístico de heridas fueron representadas, estas incluyeron heridas a arterias mayores, venas, pulmones, corazón, pericardio, esófago, diafragma, pared abdominal, estomago, intestinos, hígado, riñones, pelvis, y extremidades. Se exploraron una variedad de intervenciones quirúrgicas y no quirúrgicas. Actualmente han participado 42 instituciones desde los Estados Unidos, Brasil, Colombia, Bahamas, Canadá, México, Venezuela, Argentina, Panamá, Puerto Rico, República Dominicana, Islas Vírgenes de EE.UU, España, Tailandia, Turquía e Irak; desde centros médicos académicos y militares, hospitales comunitarios, y hospitales rurales. En el año 2011 la serie fue acreditada por el Consejo de Acreditación para la Educación Médica Continuada.

Conclusiones: La telemedicina ofrece una solución a la desigualdad de acceso a cuidados y educación traumatológica. La diversidad de configuraciones institucionales le permite a los participantes aprender cómo cuidar mejor de victimas de traumatismo, sin importar las diferencias en recursos y experiencia. Además de funcionar como una herramienta educativa, la serie proporciona un mecanismo para que los médicos interactúen y creen redes de colaboración para proyectos en el futuro.

Palavras claves: Telemedicina, Trauma, Educación quirúrgica, Videoconferencias, Educación a distancia, Grand rounds

\section{INTRODUCTION}

There are inherent differences in trauma care and education across the world. With traumatic injuries remaining

Paper presented at the General Competition, 25th Annual Congress of Panamerican Trauma Society, Medellin, Colombia, November 2012. 
a significant global burden, ${ }^{1}$ more emphasis is now directed toward the education and training of health care professionals. In trauma education, clinical case discussions and seminars are often used to promote education and knowledge exchange. Activities, such as Grand Rounds and morbidity and mortality conferences provide clinicians with the opportunity to disseminate information on the causes, treatment and outcomes of injuries. The lessons learned from challenging clinical cases discussed in these conferences can inform future best practices and decrease the likelihood of future adverse events. Typically, continuing education courses are widely available in teaching hospitals and at large, academic medical centers. Providers in smaller, rural areas do not have the same access to clinical and educational resources as those in urban areas. ${ }^{2}$ This discrepancy is even more significant in developing countries, where providers are faced with varying degrees of availability of both human and physical resources. Ultimately, these inequities can lead to poorer patient outcomes. ${ }^{3}$

Just as technology is changing how providers communicate with patients, it is also altering how providers engage in professional and educational activities. Since 2007, the William Lehman Center/Ryder Trauma Center team has been delivering trauma and critical care educational seminars domestically and internationally via telemedicine. The William Lehman Injury Research Center is an internationally recognized research facility established to improve the treatment, prevention, and rehabilitation of traumatic injuries. The Ryder Trauma Center (RTC) is the only adult and pediatric level one trauma center in MiamiDade County, treating an estimated 4,000 injured patients annually. Given its location in Miami, the gateway to Latin America and the Caribbean, the RTC is in a unique position to treat international patients as well as offer a variety of training programs to foreign health care providers. For 45 years, the William J Harrington Medical Training Program has trained the top-tier of medical professionals from Latin America and the Caribbean through placements in residency and observership programs across diverse specialties at the medical school. Upon completion, participants return to their home country to become leaders in their field.

The International Trauma Tele-Grand Rounds is a weekly series of complex trauma case presentations and advanced trauma and critical care topics. Through the use of multipoint videoconferencing, sites across the world can connect simultaneously to participate in these interactive sessions. The main objective of the Tele-Grand Rounds is to provide physicians, trainees and medical students with an outstanding tool to share medical expertise. Participants share knowledge for the optimal care of trauma patients based on best practices and lessons learned. This paper will review our experience running the series from its inception, to how it has evolved over the years. Program data from a 2-year time frame will be presented.

\section{MATERIALS AND METHODS}

Teleconference data was gathered from qualitative reports, research documents and data tables. We retrospectively reviewed program data from teleconferences held from January 2010 to December 2011. Prior to those years, program data was not collected systematically; therefore we extracted available historical information from qualitative reports and other conference documents.

Conferences are held on a weekly basis, on Fridays, with each week a different institution presenting a trauma case. A schedule is created at the beginning of each semester with presenting institutions, and the week prior to each conference a telemedicine coordinator works with the presenter on obtaining the title and objectives for the presentation. The day of the presentation, multiple sites connect simultaneously through our institution's network bridge. The format of the presentation captures the full management of a trauma patient, from the prehospital phase to discharge. Key points include mechanism of injury, resuscitation, laboratory and imaging diagnostics, surgical and nonsurgical interventions and postoperative care. Presenters pause frequently to ask the group what the next steps should be, allowing for discussions and evaluation of different treatment options. A moderator at the hosting institution facilitates the process to ensure group participation. Presentations are highly interactive, which gives participants the ability to survey differences in trauma care across international health systems. Participants fill out questionnaires after each conference regarding the objectives and content of the presentations. Continuing medical education (CME) credits are provided for participating physicians.

\section{RESULTS}

Our experience with teleconferences began as a small collaboration with a small number of institutions in Brazil (University of Campinas, Santa Casa, State University of Amazonas, University of Sao Paulo) and the RTC. Overtime, a small network was collegially formed and conferences increased in frequency and quality. Initially videoconferences were held connecting two parties in a point to point manner utilizing a dedicated ISDN line. This was done in order to avoid firewall issues and ensure a secure connection between both sites. Around the same time, RTC began conducting teleconferences with the US military, given their long-standing relationship. Since 2001, the Army Trauma Training Center has been training 
Forward Surgical Teams (FSTs) prior to their deployment to Iraq or Afghanistan. The FSTs rotate through the trauma center to enhance their clinical skills and teamwork. Military medical personnel have unique educational needs given the inevitable differences that exist in civilian and battlefield settings. Not all military physicians, nurses and medics have the opportunity to train in combat scenarios. Therefore, a training gap often occurs in military medical education. ${ }^{4}$ In order to address this gap, a program was created to deliver trauma and critical care lectures to military clinicians in remote areas. In 2008 to 2009 , interactive conferences were held via a two-way videoconferencing system between the trauma center and the Air Force 1st Special Operations Support Squadron at Hurlburt Field, Florida. This educational program consisted of lectures in trauma surgery and anesthesiology developed specifically to military clinicians. CME credits were provided for their participation.

Due to the success of the tele-educational program with the military, we began to shift our focus back to the international network of institutions in order to continue providing educational conferences via telemedicine. A turning point in the growth of the conferences occurred in parallel with advancements in technology. We began using a Polycom ${ }^{\circledR}$ MGC-100 multipoint control unit (MCU) that allowed for more than two sites to connect to a virtual conference room. Currently the technology has evolved further and conferences are hosted using Polycom ${ }^{\circledR} \mathrm{RMX}^{\circledR}$ $2000 \mathrm{MCU}$ which can use IP network (H.323 and SIP) and ISDN/PSTN. Through this unit we are capable of accepting multiple high definition and standard definition calls using a continuous presence mode, allowing sites to see each other while also sharing a separate stream for the content (Powerpoints, videos, images). The acquisition of a high performance MCU has been instrumental in the growth and improvement of the conference.

In the middle of 2010 , the frequency of the series increased to a weekly event, and 12 other sites joined the network. Systematic procedures were established to collect program data from the conferences, such as what and how many sites connected, and descriptive information from each case. By 2011, the network experienced another growth spurt and the series received accreditation from the Accreditation Council for Continuing Medical Education. During 2010 to 2011, 68 sessions were documented. Cases include blunt (42.6\%), penetrating (48.5\%), blast (7.4\%) and crushing $(1.5 \%)$ traumas. Gunshot wound injuries were the most frequent (25\%). Tables 1 and 2 show the frequency and distribution of the types of trauma presented. Table 3 demonstrates the variety of injuries. A holistic range of injuries is represented including injuries vascular, abdominal, thoracic and orthopedic injuries. Due to the wide array of injuries, a variety of surgical and nonsurgical interventions have also been discussed in these conferences. On average, $7.2( \pm 2.1)$ sites participate on a weekly basis. To date, we have had institutions participate from all over the world: United States, Brazil, Colombia, Bahamas, Canada, Mexico, Venezuela, Argentina, Panama, Puerto Rico, Dominican Republic, British Virgin Islands, Spain, Thailand, Mexico, Turkey and Iraq (Fig. 1). Institutions have ranged from large, academic medical centers to community hospitals, rural centers and military hospitals.

\begin{tabular}{|c|c|c|c|c|}
\hline \multicolumn{5}{|c|}{ Table 1: Distribution of trauma type } \\
\hline & Blunt & Penetrating & Blast & Crushing \\
\hline 2010 & 7 & 12 & 1 & 0 \\
\hline 2011 & 22 & 21 & 5 & 1 \\
\hline Total & 29 & 33 & 6 & 1 \\
\hline
\end{tabular}

Table 2: Distribution by trauma type and traumatic agent

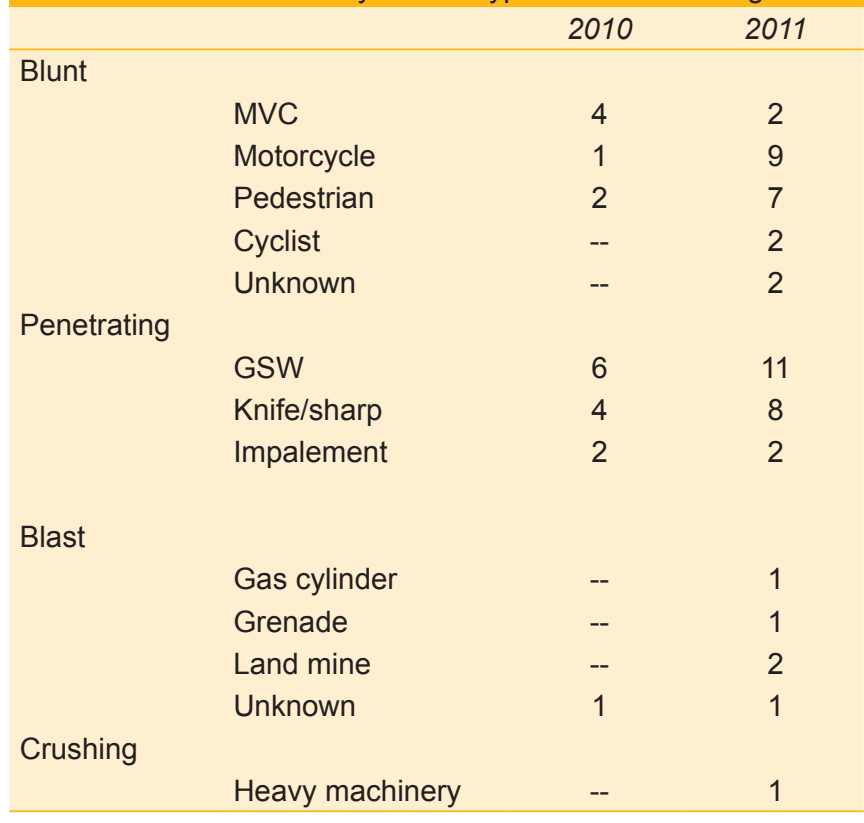

\begin{tabular}{lcc}
\multicolumn{3}{c}{ Table 3: Distribution of injury locations } \\
Injury location & 2010 & 2011 \\
\hline Abdomen & 2 & 2 \\
Aorta & 1 & 2 \\
Axillary artery & - & 1 \\
Carotid artery & - & 1 \\
Chest & - & 3 \\
Colon & - & 3 \\
Diaphragm & 2 & 2 \\
Duodenum & 1 & 1 \\
Esophagus & - & 2 \\
Extremities & 2 & 1 \\
Face & 1 & 1 \\
Head & 1 & 1 \\
Heart & 1 & 2 \\
Hepatic artery & - & 1 \\
& & Contd.
\end{tabular}




\begin{tabular}{lcc} 
Contd. & & \\
Iliac artery & - & 2 \\
Infrarenal aorta & - & 1 \\
Knee & 1 & - \\
Liver & 2 & 4 \\
Lungs & - & 5 \\
Mesenteric vein & - & 1 \\
Pancreas & 1 & 1 \\
Pelvis & - & 5 \\
Pericardium & - & 1 \\
Renal artery & - & 1 \\
Small bowel & 1 & 1 \\
Subclavian artery & - & 1 \\
Spleen & - & 3 \\
Thoracoabdominal (unspecified) & 1 & 3 \\
Unknown & 1 & - \\
Vena cava & 1 & - \\
\hline Total & 19 & 52
\end{tabular}

\section{DISCUSSION}

Telemedicine is transforming how trauma care and education is delivered across the world. The use of teleconferences to extend the reach of Grand Rounds has given us the opportunity to broaden our collaboration with other institutions, forming a network of medical experts with a strong sense of collegiality. The Tele-Grand Rounds is continuously growing, and new sites are encouraged to join on a regular basis. In addition to serving as an educational tool, the weekly series provide a mechanism for physicians from different institutions to network and collaborate on new research projects, presentations, and future professional endeavors. In 2011, the Panamerican Trauma Society has recognized the Tele-Grand Rounds as one of their educational activities. Some institutions that participate in the International Grand Rounds also have formed teleconferences in their home countries, such as the one supported by the Brazilian Society of Integrated Trauma Care (SBAIT).

The use of videoconferencing for the distribution of educational material is nothing new. Distance education has long been regarded as an effective means to reduce the educational isolation of providers. ${ }^{5}$ In the literature, there are increasing reports of different tele-educational programs in other specialties such as surgery, ${ }^{6}$ gynecology, ${ }^{7}$ and urology ${ }^{8}$ among others. To the best of our knowledge, the International Trauma Tele-Grand Rounds is unique in trauma. The TeleGrand Rounds arose to address critical training gaps in the current education and training of surgical residents and fellows. Changes in surgical practice and limitations on residency work hours have impacted surgical education, often limiting trainees' exposure to complex trauma cases. ${ }^{9}$ The Trauma Tele-Grand Rounds focuses on challenging cases that offer participants the opportunity to learn how to treat injuries perhaps otherwise missed during surgical residency. Moreover, this is done through international collaborations further enhancing the educational potential and reach of the conferences.

Our experience during the past 5 years has taught us many lessons. Therefore, we provide the following technical and program recommendations necessary to run a successful tele-educational program:

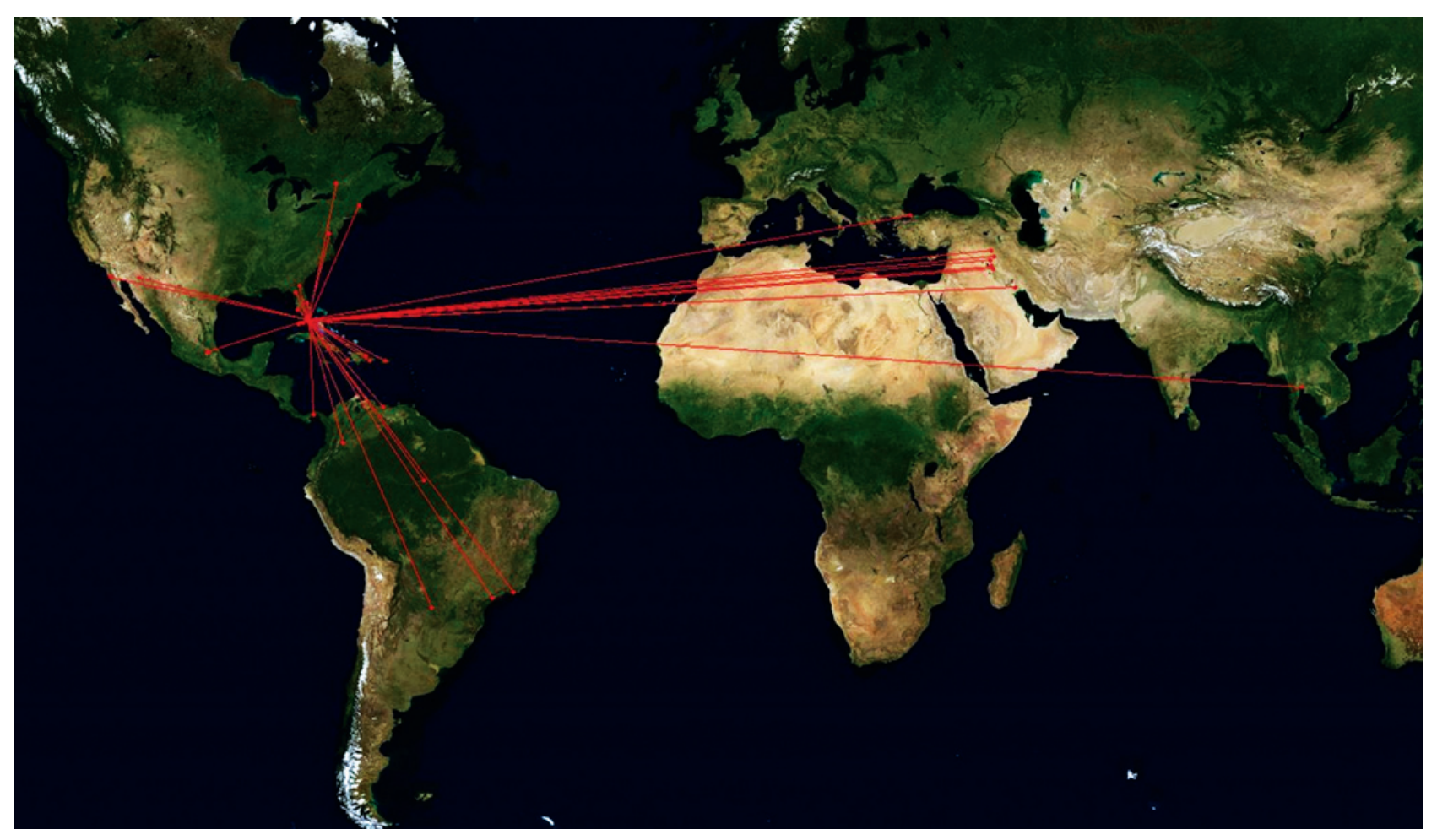

Fig. 1: Distribution of sites around the world 
- Technology becomes outdated as quickly as it advances. It is imperative to keep up with the latest trends, gadgets and equipment out in the market. We experienced tremendous growth in our program once we obtained the appropriate technology to handle multipoint conferencing.

- The right technical support, preferably a network engineer or a professional who understands how networks function, is imperative to your program's success. At the far end, it is also helpful to have a dedicated information technology staff to help with the calls. This is especially important when issues of firewalls and security appear. Due to the strict protocols used to protect the integrity of hospital communication and information networks it is necessary that participants have the support of their information technology and networking departments in order to troubleshoot any issues with firewall traversal.

- Program data should be collected early on and in a systematic fashion in order to appropriately evaluate the progress, attendance and content of your program.

The International Trauma Tele-Grand Rounds has evolved tremendously since its early days. Future directions include implementing mechanisms to distribute the literature and evidence base discussed during the conferences, as well as create a repository of recorded teleconferences that can be accessible at any time. The ultimate goal is to unite medical minds throughout the world, regardless of distance, with the hopes that ultimately trauma patients will gain the most benefit.

\section{REFERENCES}

1. Peden M, McGee K, Krug E. Injury: A leading cause of the global burden of disease. World Health Organization, Geneva 2002.

2. Jukkala AM, Henly SJ, Lindeke LL. Rural perceptions of continuing professional education. J Contin Educ Nurs 2008;39(12):555-63.

3. Zonies D, Maier RV, Civil, I, Eid A, Geisler BP, Guerrero A, et al. Trauma and Burn Education: A Global Survey. World J Surg 2012;36:548-55.

4. Leitch RA, Moses GR, Magee H. Simulation and the future of military medicine. Mil Med 2002;167(4):350-54.

5. Zollo SA, Kienzle MG, Henshaw Z, Crist LG, Wakefield DS. Tele-education in a telemedicine environment: Implications for rural health care and academic medical centers. J Med Syst 1999;23(2):107-22.

6. Ereso AQ, Garcia, P, Tseng E, et al. Live transference of surgical subspecialty skills using telerobotic proctoring to remote general surgeons. J Am Coll Surg 2010;211(3):400-11.

7. Spitzer RF, Kives S, Ornstein M, Caccia N, Stephens D, Flood C, Allen LM. Videoconferencing for resident teaching of subspecialty topics: The pediatric and adolescent gynecology experience at the hospital for sick children. J Pediatr Adol Gynecol 2008;21(6):343-46.

8. Cook A, Pippi Salle J, Reid J, Chow KF, Kuan J, Razvi H, et al. Prospective evaluation of remote, interactive videoconferencing to enhance urology resident education: The genitourinary teleteaching initiative. J Urol 2005;174(5):1958-60.
9. Sachdeva AK, Bell RH Jr, Britt LD, Tarpley MJ. National efforts to reform residency education in surgery. Acad Med 2007 Dec;82(12):1200-10.

\section{ABOUT THE AUTHORS}

\section{Antonio C Marttos}

Assistant Professor, Department of Surgery, Division of Trauma Surgery and Critical Care; Director of Telemedicine and Global eHealth; Co-Director, William Lehman Injury Research Center, University of Miami, Florida, United States

\section{Fernanda M Kuchkarian (Corresponding Author)}

Manager, Department of Surgery, Research Support, Community Outreach and Education Research, William Lehman Injury Research Center, University of Miami, Miami, Florida, United States, e-mail: fkuchkarian@med.miami.edu

\section{Daniel F Rojas}

Research Associate, Department of Surgery, William Lehman Injury Research Center, University of Miami, Miami, Florida, United States

\section{Gustavo P Fraga}

Professor, Faculty of Medical Sciences, Department of Surgery Division of Trauma Surgery, Chief of School of Medical Sciences University of Campinas (FCM/UNICAMP), Campinas, São Paulo Brazil

\section{Francisco S Collet-Silva}

Professor, Department of Surgery, Hospital das Clínicas da Faculdade de Medicina, University of São Paulo, São Paulo, Brazil

\section{Cleinaldo de Almeida Costa}

Professor, Director, Health Sciences College, State University of Amazonas (UEA), Manaus, Brazil

\section{George D Garcia}

Assistant Professor, Department of Surgery, University of Miami Miami, Florida, United States

\section{Enrique Ginzburg}

Associate Professor, Department of Surgery, Director, International Health Center, The Hague, Netherlands; Surgical Director Neurosurgery Intensive Care Unit, University of Miami, Miami Florida, United States

\section{Carl I Schulman}

Associate Director, Department of Surgery, Surgical Residency Training Program; Associate Professor, Department of Clinical Surgery; Co-Director, William Lehman Injury Research Center University of Miami, Miami, Florida, United States

\section{Nicholas Namias}

Chief, Division of Trauma, Professor, Department of Surgery University of Miami, Florida, USA 